\title{
Políticas Públicas de Turismo: uma Análise dos Circuitos Turísticos de Minas Gerais sob s Concepção de Cluster
}

\author{
Tourism Public Policies: an analysis of Minas Gerais Touristic Circuits using \\ cluster concept
}

\author{
Bruno Martins Augusto Gomes ${ }^{1}$ \\ Valdir José da Silva ${ }^{2}$ \\ Antônio Carlos dos Santos ${ }^{3}$
}

\begin{abstract}
Resumo
Diante da atual competitividade da economia é inevitável que as organizações que compõe cadeia produtiva do turismo busquem novas formas de atuar. Uma forma das organizações adquirirem vantagens competitivas frente ao mercado é através dos clusters. Percebendo essa tendência, o governo do estado de Minas Gerais passou a desenvolver políticas públicas de incentivo à articulação regional do turismo. Por isso, esse trabalho busca analisar a política de implantação e o desenvolvimento dos circuitos turísticos de Minas Gerais a partir da concepção de cluster. Realizou-se um levantamento bibliográfico e uma pesquisa junto aos diretores e gestores dos circuitos. Após as análises dos dados, conclui-se que as iniciativas do governo de Minas coincidem com os princípios de cluster, porém os circuitos ainda estão em fase de implantação, dificultando que esse conceito seja totalmente implementado.

Palavras-Chave: turismo; política pública; cluster
\end{abstract}

\begin{abstract}
In actual competitive economy the organizations that it composes your productive chain seek competitiveness. A form of the organizations acquire advantages competitive front to the market it is through the clusters. Noticing that tendency, the government of the state of Minas Gerais started to develop public politics of incentive to the regional articulation of the tourism. A bibliographical rising and a research with the directors and managers of the circuits were made. After analysis the collected data, it is ended that the Minas Gerais government's initiatives coincide with the cluster beginnings, however the circuits are still in implantation phase, hindering that that concept is totally implemented.
\end{abstract}

Keywords: tourism; public politic; , cluster

\footnotetext{
${ }^{1}$ Bacharel em Turismo pela Universidade Federal de Ouro Preto. Mestre em Administração na Universidade Federal de Lavras. Professor da Universidade Federal do Paraná, PR. E-mail: gomesbma@yahoo.com.br

${ }^{2}$ Mestre em Extensão Rural na Universidade Federal de Viçosa. Professor da Escola Agrotécnica Federal de Barbacena, MG: E-mail: valdir@fasar.com.br

3 Doutor em Administração pela Universidade de São Paulo. Professor Adjunto do Departamento de Administração da Universidade Federal de Lavras. E-mail: acsantos@ufla.br.
} 


\section{Introdução}

O mundo contemporâneo está marcado pelos avanços tecnológicos, pela informação e a conseqüente globalização. Inseridos nesse ambiente os mercados são continuamente manipulados e transformados por estratégias criadas em computador, pelas percepções subjetivas de analistas influentes e por acontecimentos políticos em qualquer parte do mundo (CAPRA, 2002).

Diante desse ambiente as organizações se encontram em uma situação altamente complexa. A distância física não mais as isola dos concorrentes e das influencias externas. As organizações que não se adaptam ao comportamento variável e globalizado do mercado estão sujeitas à falência. Para vencerem esta nova estrutura as organizações estão se articulando com outras do mesmo setor localizadas próximas.

O setor do turismo $\mathrm{O}$ setor do turismo está cada vez mais inserido na economia mundial, por isso é inevitável que a sua dinâmica de funcionamento também seja afetada por estas transformações. Além disso, o turismo é um sistema onde suas partes estão integradas e se influenciam. Para vencerem no atual mercado globalizado, as organizações turísticas estão percebendo a importância de se articularem regionalmente para adquirirem vantagens competitivas frente aos concorrentes. Consciente das transformações no mercado e visando o crescimento da atividade no estado, o governo de Minas Gerais implantou a política de turismo denominada Circuitos Turísticos. Esta política busca agrupar organizações ligadas ao turismo localizadas em uma região com características turísticas própria, formando um produto turístico integrado. Por isso o presente trabalho tem por objetivo analisar a política de turismo do governo de Minas Gerais, fundamentando-se na concepção de cluster.

Percebe-se entre estudiosos uma resistência à abordagem positivista nas ciências sociais. Mas diante da proposta de análise da política pública de turismo fundamentada na concepção de cluster optou-se pelo Survey. Segundo Alencar (2003) esta ferramenta de pesquisa é tipicamente utilizada para estudar a adoção de inovações.

Os dados foram coletados através de questionário semi-estruturado, entrevista, pesquisa bibliográfica e pesquisa documental. As entrevistas foram realizadas com diretores da Secretaria de Estado do Turismo de Minas Gerais, estruturadas a partir de um roteiro de perguntas. Os questionários foram enviados por correio eletrônico aos gestores dos circuitos. Giddens (2001) argumenta que há uma alta freqüência de questionários não respondidos 
quando estes são enviados por correspondência. Contudo, nesta pesquisa acredita-se que este instrumento de coleta de informações a alcançou bom êxito. Foram enviados questionários aos 35 circuitos que possuíam correio eletrônico cadastrado na Secretaria de Estado do Turismo de Minas Gerais, sendo que, 09 foram respondidos.

É importante destacar que de acordo com os critérios para a certificação estabelecidos pela Setur-MG, os circuitos que responderam estão entre os 10 mais avançados. Constam 45 circuitos nos registros da Setur-MG. Mas destes, 10 não ultrapassaram a etapa inicial das oficinas realizadas pela Setur e, portanto não estavam atuando. Para cumprir o objetivo da pesquisa o questionário abordou questões como: quais as modalidades de empresas que participam do circuito; a freqüência das reuniões entre os associados, as dificuldades na gestão de um circuito; a existência de cooperativismo entre associados. Para cumprir o objetivo proposto

Dessa forma, o artigo se estrutura, em uma introdução referencial teórico, em que se estuda estuda o modelo de Sistema Turístico proposto por Beni, buscando demonstrar o funcionamento do fenômeno do turismo. Em seguida foi feita uma contextualização das políticas públicas de turismo no Brasil e em Minas Gerais. Finalmente faz-se um estudo sobre a concepção de cluster, analisando este como estratégia de organização do turismo. $\mathrm{Na}$ "Discussão dos Resultados" foi feita uma análise da gestão dos circuitos turísticos diante da concepção de cluster. Também se comparou as exigências da Setur-MG com os propósitos da concepção de cluster.

\section{O Turismo sob a Visão Sistêmica}

Considerando a abordagem de Beni (2001), pode-se compreender o turismo como um fenômeno formado pelo conjunto de fatos relacionados ao deslocamento e permanência de pessoas, por um tempo limitado, em locais diferentes de sua residência. Durante este deslocamento as pessoas demandam produtos e principalmente serviços, causando impactos não apenas econômicos, mas também sociais, culturais e ecológicos.

Dessa forma, o estudo do turismo se pautará na visão sistêmica, amplamente utilizada em estudos turísticos no Brasil. A partir dessa abordagem é possível se ter uma visão holística do fenômeno. Será utilizado como referência o sistema turístico elaborado por Mário Beni 
(2001). Nesse modelo, denominado Sistur, o referido autor buscou relacionar as funções inerentes à natureza da atividade do turismo e as estruturou em três conjuntos: conjunto das relações ambientais, conjunto da organização estrutural e o conjunto das ações operacionais (Figura 01).

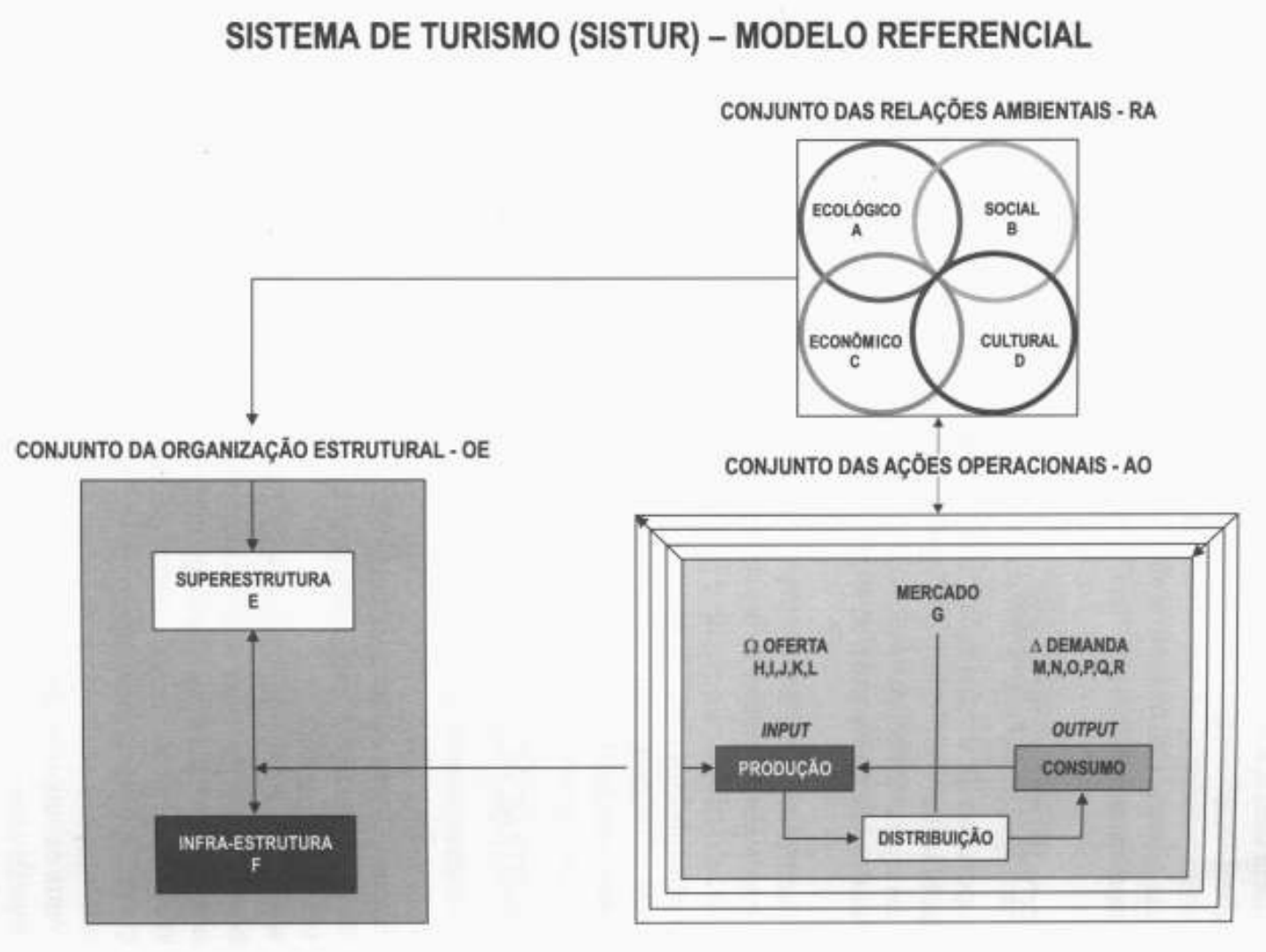

FIGURA 01: Sistema de Turismo (SISTUR) - Modelo Referencial

Fonte: BENI, 2001, p. 48.

O Conjunto das Relações Ambientais é formado pelos subsistemas ecológico, social, cultural e econômico. Ele tem grande importância, pois seus componentes representam o funcionamento harmônico da atividade turística. Esta harmonia é obtida quando os quatro componentes deste conjunto (subsistema ecológico, cultural, social e econômico) se relacionam sem que um se imponha sobre os demais. Eles precisam atuar de forma integrada e equilibrada.

Este equilíbrio evita que ocorram danos sociais, culturais, ecológicos e econômicos aos envolvidos no fenômeno do turismo. A este turismo desenvolvido de maneira equilibrada e 
com a participação igual de todos os componentes do Conjunto das Relações Ambientais, é denominado turismo sustentável.

O Conjunto das Organizações Estruturais compreende: as políticas públicas e privadas relacionadas ao funcionamento do Sistur (subsistema da super estrutura) e também o subsistema da infra-estrutura.O subsistema da infra-estrutura envolve a infra-estrutura geral (utilizada por todos os setores) e a específica que atende exclusivamente as necessidades do setor turístico.

O Conjunto das Ações Operacionais envolve a dinâmica de atuação das organizações que compõe o Sistur. Nesse ambiente estão inseridos os subsistemas de mercado, oferta, produção, distribuição, demanda, e consumo.

Este estudo desenvolve-se predominantemente nestes dois últimos conjuntos, pois a política de circuitos turísticos constitui-se numa ação do poder público, visando a articulação regional das organizações ligadas ao turismo para atuarem no mercado. Contudo, a política estadual e as ações das organizações turísticas devem se pautar no Conjunto das Relações Ambientais.

\section{As Políticas Brasileiras para o Turismo}

Para que o turismo se desenvolva em um local, a participação do poder público é fundamental, através principalmente das políticas e planos de turismo. De acordo com Cruz (2001) a política deve anteceder o plano sendo ela um conjunto de diretrizes e ações deliberadas pelo poder público, com o objetivo de ordenar o desenvolvimento da atividade turística em um determinado território.

Segundo a mesma autora, do ponto de vista das políticas públicas a história do turismo no Brasil pode ser dividida em três fases. A primeira ação do governo brasileiro visando regulamentar a atividade ocorreu em 1938 com o Decreto-lei 406 que determinava que a venda de passagens aéreas só poderia ser feita por empresas autorizadas pelo Ministério de Trabalho, Indústria e Comércio.

Segundo Acerenza (2002) para conhecer a importância do turismo perante aos outros setores da economia de uma região, pode-se observar a hierarquia (Ministério, Departamento, Escritório, Comissão) na administração pública. Por isso, percebe-se que nesse período o 
turismo no Brasil não recebia muita atenção do governo. Não existia um órgão específico para ordenar e fiscalizar a atividade, quem desempenhava tal função era o Ministério do Trabalho, Indústria e Comércio.

Ao longo dos anos, o turismo no Brasil esteve sob a responsabilidade de diversos órgãos do governo federal. Apenas em 1966, segunda fase das políticas nacionais de turismo, o Decretolei 55/66 cria o Sistema Nacional de Turismo. Este sistema era composto pelo CNTUR e a EMBRATUR.

A EMBRATUR era responsável por estudar e propor ao CNTUR os atos necessários para promover a política nacional de turismo enquanto ele formularia as diretrizes desta política. A divulgação do país era responsabilidade do Ministério das Relações Exteriores. Esta política foi elaborada pelo CNTUR em consonância com o Plano de Ação Econômica do Governo (Castelo Branco) que buscava minorar as diferenças econômicas e sociais do país. Acreditasse ser esta uma das primeiras vezes no Brasil que o turismo é visto como uma atividade capaz de atenuar os desníveis sociais.

Com o passar dos anos a EMBRATUR adquire maior poder político e no governo de Collor de Melo (1990-1992) inicia-se a terceira fase do turismo brasileiro. O CNTUR é extinto e a EMBRATUR passa a ser responsável pela formulação e execução das políticas nacionais de turismo. Também no governo Collor foi elaborado o Plano Nacional de Turismo (Plantur), que contemplava dentre outros programas, o Programa de Pólos Turísticos. Este plano não obteve êxito, pois não foi instituída uma política de turismo que o fundamentasse.

Apenas no governo de Fernando Henrique Cardoso foi adotada uma política de turismo. Esta política possuía dentre suas estratégias, a descentralização da gestão turística, através do PNMT. O Plano Nacional de Municipalização do Turismo (PNMT) foi um plano utilizado por este governo com o intuito de implantar uma gestão do turismo descentralizada, uniformizada e integrada. O governo federal distribuiu responsabilidades para o setor privado, estados e municípios. O PNMT foi muito importante porque deu início à gestão participativa do turismo, arraigou no meio turístico brasileiro a importância dos Conselhos Municipais de Turismo e iniciou o processo de exigir dos municípios que se organizem para receberem recursos governamentais. Mas no segundo mandato de Fernando Henrique suas ações não tiveram continuidade. 
No governo Lula, pode-se acrescer a quarta fase do turismo no país. Criou-se um Ministério exclusivo para o Turismo, a EMBRATUR teve sua função repensada e foi elaborado o Plano Nacional de Turismo (PNT).

A elaboração do atual Plano Nacional de Turismo (PNT) se deu de forma participativa, contando com a colaboração de representantes do setor privado, secretários estaduais de turismo, pesquisadores e inúmeras entidades de classe como ABBTUR, ABAV, ABIH, SENAC entre outras.

O plano foi elaborado com o objetivo diversificar e ampliar os produtos turísticos brasileiros, prezando pela qualidade, a competitividade e contemplando as diversidades regionais. $\mathrm{O}$ governo espera que através do PNT o turismo brasileiro atinja até o ano de 2007 metas

bastante audaciosas. É esperado, por exemplo, a criação de 1 milhão de empregos, 7,5 milhões de turistas/ano e 65 milhões de desembarques em vôos domésticos. Pretende-se também formular no mínimo três produtos de qualidade em cada estado brasileiro, atingindo um total de 81 produtos ofertados.

O Plano Nacional de Turismo é organizado em sete macroprogramas: Gestão e Relações Institucionais, Fomento, Infra-estrutura, Estruturação e Diversificação da Oferta Turística, Qualidade do Produto Turístico, Promoção e Apoio a Comercialização Informações Turísticas. Dentro de cada macroprograma existem programas específicos elaborados para solucionar problemas detectados, que interferem no desenvolvimento do turismo brasileiro.

Cabe destacar o Macroprograma de Estruturação e Diversificação da Oferta Turística já que um de seus programas busca formar de roteiros integrados. Ele é voltado para a regionalização do turismo, onde os municípios se associam e consequentemente surgem pólos. Além dessa estratégia o programa também prevê a realização do Inventário da Oferta Turística Brasileira e prima por processos participativos e descentralizados. Está previsto o estabelecimento de parcerias, incluindo instituições de ensino superior que contribuirão com conhecimentos técnicos científicos e na realização do inventário da oferta turística.

\section{Políticas Mineiras para o Turismo}

Em Minas Gerais, até o final da década de 1990 nunca tinha sido elaborada nenhuma política de turismo. Até então as ações governamentais no estado limitaram-se à criação da Águas de 
Minas Gerais - Hidrominas, responsável pelo fomento à atividade até 1972; criação do Conselho Estadual de Turismo e Superintendência de Turismo; elaboração do Plano Mineiro de Desenvolvimento Econômico e Social.

No governo de Itamar Franco (1999-2002) foi criada a Secretaria de Estado do Turismo, surgiu o Instituto Estrada Real com apoio do governo estadual e foi elaborada a política de turismo para o estado tendo como eixo principal a criação dos Circuitos Turísticos.

A Estrada Real constitui-se em duas vias oficiais utilizadas nos séculos XVIII e XIX para a circulação de pessoas, mercadorias, ouro e diamante entre os estados de Minas Gerais, São Paulo e Rio de Janeiro. Para desenvolver o turismo ao longo desse trecho o governo de Minas criou o Programa de Desenvolvimento do Potencial Turístico da Estrada Real e firmou parceria com o Instituto Estrada Real (IER). O Instituto é uma organização não governamental criada pela Federação das Indústrias do Estado de Minas Gerais - FIEMG, para de recuperar e aproveitar o potencial da Estrada Real transformando-a em um produto turístico.

O estudo se deterá à outra iniciativa do governo de Minas Gerais, que é a política de incentivo à formação de circuitos turísticos regionais. Os circuitos turísticos constituem-se em um agrupamento de municípios com características turísticas semelhantes que se localizam dentro de uma região geográfica limitada. Pode se associar ao circuito poder público, iniciativa privada, instituições de ensino e terceiro setor relacionados com a atividade turística na região.

Em 2001, dois anos antes do surgimento do Plano Nacional de Turismo, o estado lançou uma política de turismo para estimular a criação de circuitos turísticos. O governo estadual já havia percebido que a importância da articulação regional para a expansão do número de produtos turísticos oferecidos pelo estado e o conseqüente aumento na taxa de permanência do turista no estado.

Fundamentada em uma política voltada para a regionalização e descentralização das decisões, a partir de 2001 a Secretaria Estadual de Turismo passou a organizar Oficinas Participativas. Elas foram o primeiro passo para os municípios se organizarem em circuitos. As oficinas discutiam a atividade turística e a importância da regionalização como instrumento de desenvolvimento turístico com o poder público e a comunidade local. Ao final dos trabalhos foram realizadas 54 oficinas, atingindo mais de 400 municípios. Nestas oficinas os 
participantes já combinavam as próximas ações necessárias para que o circuito turístico fosse criado (BOLSON, 2003).

Para formatar um circuito a Secretaria recomenda que além das afinidades, os municípios devem estar localizados num raio de $100 \mathrm{~km}$; deve ser realizada uma reunião com técnicos da Secretaria de Turismo; definir um nome para o circuito para de acordo a identidade regional; possuir a nomenclatura Circuito Turístico; definir o tipo de entidade gestora (Associação, ONG, Agencia de Desenvolvimento); elaborar e registrar um estatuto.

O circuito é administrado por uma entidade sem fins lucrativos, que possui nomenclatura "Circuito Turístico", mantida através de mensalidades pagas pelos associados. O governo de Minas Gerais reconhece estas instituições como responsáveis pelo desenvolvimento do turismo na região de abrangência de seu circuito, desde que atendam as normas de certificação estabelecidas por ele.

A política de certificação foi uma proposta do governo estadual, discutida com os representantes dos circuitos. Ficou estabelecido que o estado concederá o certificado apenas aos circuitos que realizarem o levantamento da oferta turística das cidades participantes, providenciarem a documentação e as demais exigências que constam na Resolução $\mathrm{n}^{\circ}$ $007 / 2003$.

Para ser certificado pela primeira vez, as exigências estão relacionadas à criação, registro e modo de funcionamento da entidade gestora. Também são exigidas ações mínimas para que uma entidade gestora de um circuito turístico possa funcionar como ter endereço fixo, telefone, logomarca, possuir um Bacharel em Turismo como responsável técnico, dentre outras. Após concedida, a certificação é válida por um ano. As exigências do governo para renová-la são maiores que as do primeiro ano. Além da atualização do levantamento da oferta turística e dos demais documentos, o circuito deverá implementar um plano de ação, realizar a pesquisa de demanda, organizar um calendário oficial de eventos, disponibilizar pelo menos um roteiro, ter um posto de informação turística em cada cidade do circuito dentre outras exigências. Os circuitos que se empenharem e conseguirem a certificação, receberão tratamento especial nas políticas de turismo do estado. 


\section{O Cluster como Estratégia de Organização do Turismo}

Partindo da visão sistêmica, um dos elementos de análise é a reação das organizações diante das transformações do ambiente. No passado as organizações construíam suas estratégias competitivas considerando como concorrentes e clientes apenas aqueles localizados próximos geograficamente, sendo que a relação interempresarial não era muito bem aceita. Segundo Porter apud Toledo et al. (2002), com a atual fase globalização, os fatores tempo e espaço desconfiguraram os tradicionais instrumentos de vantagem competitiva. Por isso, o mercado de atuação de uma empresa não está mais centrado apenas em suas proximidades. Com o avanço da tecnologia e a globalização da economia, este mercado pode estar localizado em qualquer continente. Uma maneira das organizações reagirem ao mercado globalizado é se articulando em clusters. Segundo Porter (1998), clusters são concentrações geográficas de empresas e instituições relacionados a um setor, que estão interligadas, que se complementam, visando alcançarem vantagens frente ao mercado.

Para a análise do agrupamento de organizações no turismo, utilizou-se esta concepção de cluster. Há pesquisadores que contestam essa abordagem. Mas Porter (1998), pesquisador considerado referência no estudo de cluster, em sua obra Clusters and the New Economics of Competition faz referências à clusters de turismo.

Toledo et al. (2002) salienta que o cluster requer essencialmente a existência da vantagem competitiva construída a partir de uma estratégia competitiva, cooperativa e uma estratégia de relacionamento com o cliente. Como percebemos na Figura 02, o crescimento da vantagem competitiva é proporcional ao aumento das estratégias de relacionamento com o cliente, competitiva, cooperativa. 


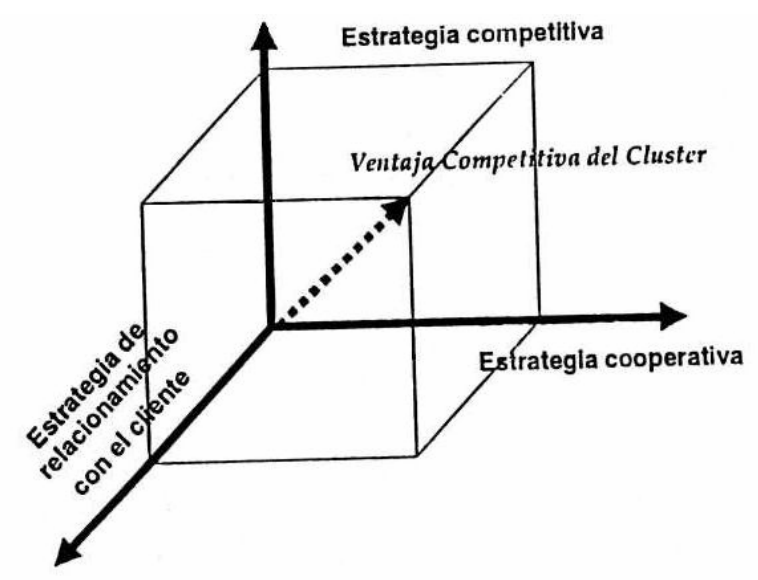

FIGURA 02 - Competitividade nas empresas de um cluster turístico Fonte: TOLEDO et al., 2002, p. 98

Nesse sentido o cluster oferece às organizações participantes as seguintes vantagens:

a) Vantagem de custo, através do cluster as empresas integrarão serviços, portanto conseguirão projetar, produzir e comercializar o produto a um custo menor que seus concorrentes.

b) Diferenciação, através da união elas poderão unificar as tecnologias e as pesquisas, oferecendo ao consumidor um produto de qualidade diferenciada.

c) Aumento da competição entre as empresas participantes do cluster, o que as estimula a estarem buscando a melhoria contínua.

d) Desenvolvimento da região onde o cluster está localizado.

e) Atrair para a região empresas novas que trarão novos pensamentos.

f) Melhor elaboração de idéias através compartilhamento de conhecimentos e experiências.

g) Ampliação do mercado de atuação das organizações em função da elaboração de novos produtos.

h) Empresas cuja marca está decadente podem reafirmar-se ao participarem de cluster forte. 
i) Maior força para defender os direitos da categoria junto aos órgãos governamentais.

j) Melhoria nos recursos de conhecimento, pois universidades e institutos de pesquisa desenvolverão trabalhos voltados para a área de atuação do cluster.

1) Redução de custos com transporte de insumos. Um grupo forte de empresas concentrado numa região atrairá para o local os seus fornecedores.

m) Maior disponibilidade de capital financeiro para investimentos Atuando em cluster as empresas podem unir os recursos para realizarem investimentos maiores.

O bom relacionamento entre as empresas, que deve existir dentro do cluster, é uma vantagem competitiva. De nada adianta um grupo de empresários se organizarem na forma de cluster se na prática estão constantemente em conflito, desejando beneficiar-se mais que o outro. Por isso, a entidade gestora deve incentivar o diálogo e a troca de informações entre as empresas. Para tanto podem ser organizados eventos ou até mesmo, grupos de discussão na internet. Estes contatos devem buscar atenuar as relações de rivalidade existentes, eliminar o receio que os empresários têm de trocarem informações, aumentando a confiança mútua entre eles. Eles devem perceber que promovendo o intercâmbio de idéias o benefício será maior e atingirão todos os envolvidos.

Acredita-se que para coordenar as ações deve ser criada uma entidade gestora do cluster. Esta entidade será composta principalmente pelos empresários e pelo poder público. O planejamento de ações é o primeiro passo a ser realizado pela entidade gestora. Ela também deve estabelecer um padrão de qualidade para os produtos e serviços oferecidos pelo cluster, acompanhando sempre o trabalho das empresas componentes e oferecendo cursos de qualificação da mão de obra e da produção. Esse acompanhamento faz-se necessário, pois caso uma empresa ofereça produtos ou serviços defeituosos todas as outras empresas do cluster podem ter sua imagem comprometida.

O cluster deve estar aberto a qualquer nova empresa que deseje participar dele, desde que se adeqüe aos padrões de qualidade estabelecidos. Para passar por essas adequações os administradores das novas empresas associadas devem estar abertos a mudanças. Eles precisam ver que em longo prazo as transformações trarão maiores benefícios para todos. Porém, para que as empresas tenham vontade de participar deve ser mostradas a elas as vantagens competitivas que são alcançadas quando atuam em grupos. 
De acordo com dados do Cluster de Entretenimento da Bahia (CLUSTER S/D), na sua implantação foram contatadas mais de 600 empresas, porém apenas 11 aderiram ao cluster. Por isso, para formar um cluster deve ser convidado um número expressivo de empresas. Mas antes de convidar as empresas para participarem, deve ser feita uma pesquisa com o intuito de identificar as necessidades dos empresários, o nível de conhecimento que possuem acerca de cluster e como é a relação entre empresas da região. Enfim, devem ser coletados dados que embasem uma proposta atraente de adesão ao cluster.

Para o desenvolvimento do cluster é fundamental a presença de universidades. Elas irão realizar pesquisas, formar profissionais qualificados, ministrar cursos de treinamento para os trabalhadores e oferecer estagiários. As universidades sanam uma grande necessidade das empresas que é falta de dados estatísticos confiáveis ao passo que as empresas podem financiar trabalhos científicos.

O sucesso de um cluster depende de uma boa gestão das externalidades (PETROCCHI,2001). Por isso, cabe a entidade gestora do cluster e as empresas participantes estarem atentas às tendências do mercado para que não sejam surpreendidas por inovações e mudanças do meio externo. Caso essas alterações ocorram, ela deve saber se adaptar à nova situação. É notável que existem situações difíceis de prever, por exemplo, o atentado em 11 de setembro de 2001, que de maneira súbita causou impactos na economia e principalmente no setor de turismo.

A atual estrutura política predominante no país oferece alguns obstáculos ao desenvolvimento das atividades de um cluster, dentre os quais estão: a constante mudança das políticas governamentais em função da troca de mandatos; a não compatibilidade entre o tempo necessário para um destino turístico obter êxito e a necessidade que a maioria dos políticos tem de realizar tarefas que exibam resultados imediatos. De forma alguma o poder público deve ausentar-se na constituição de um cluster, porém acredita-se que deve ser priorizado a participação de funcionários públicos efetivos. Assim, trocam-se os mandatos, mas os trabalhos não são interrompidos, evitando também que bons trabalhos sejam paralisados devido a interesses políticos divergentes.

Contudo, Amato Netto (2001) nos alerta para outro grande desafio na implantação de clusters no Brasil. De acordo com o autor, os empresários brasileiros têm um comportamento individualista, de perspectivas de curto prazo, de lucros imediatos e de grande desconfiança 
com relação ao estabelecimento de alianças estratégicas, parcerias ou de outros tipos de associações interempresariais, o que obstem a instalação de clusters no país.

\section{Resultados e Discussão}

De acordo com os gestores entrevistados as principais dificuldades enfrentadas na gestão de um circuito são: falta de recursos financeiros; falta de infra-estrutura básica; baixo apoio da Setur-MG para consolidar os circuitos; baixa participação do poder público e privado; descontinuidade dos trabalhos desenvolvidos pelos governos passados; falta de conhecimento sobre turismo por parte da população local; escassez de mão de obra qualificada; baixa divulgação do circuito, do estado e do país; pouca integração entre os prefeitos; baixa integração dos circuitos; falta de credibilidade do turismo, por parte dos prefeitos e empresários, como setor confiável para realização de investimentos. Dentre estes itens, os mais mencionados foram a baixa participação dos agentes locais, a pouca integração entre os municípios e entre os circuitos.

Dos circuitos pesquisados, $55 \%$ relataram não possuir plano de qualificação para os produtos oferecidos. Os que possuem, disseram que ele está sendo implementado através de instituições como Instituto Estrada Real, Senac, Sebrae, Instituto de Hospitalidade. Também se constatou que $66 \%$ não possuem roteiros de visitação formatados.

Bem como nos clusters de outras atividades econômicas, os circuitos turísticos requerem a participação não só de empresas privadas como também de universidades, instituições de pesquisa, sociedade civil e principalmente do poder público. As instituições de ensino, em especial as voltadas para o turismo, têm desenvolvido um papel primordial na implementação da política de circuitos. Todos os circuitos entrevistados acreditam que elas podem contribuir consideravelmente. Segundo eles esse apoio é importante para: realizar pesquisas; formatar roteiros turísticos; operacionalizar eventos; realizar estudos de viabilidade; realizar planejamento turístico; implementar projetos; promover um desenvolvimento sustentável do turismo; auxiliar na implantação de Conselhos Municipais de Turismo.

Segundo Petrocchi (2001) para que as empresas possam atuar de forma competitiva, o governo deve criar condições favoráveis ao turismo, elaborando diretrizes para o futuro do destino turístico, planejando o uso do solo, criando condições de segurança e diligenciando 
para que se preserve o meio ambiente. Verificou-se que o relacionamento entre o poder público e a iniciativa privada, dentro dos circuitos é bom. Nenhum dos entrevistados a classificou como muito boa. As ações do estado do governo de Minas e o apoio da Setur-MG aos circuitos são classificados por aproximadamente $45 \%$ dos entrevistados como muito bom e bom.

A maioria dos circuitos entrevistados classifica o cooperativismo e a troca de informações entre os associados como médio. A competitividade interna das organizações, em busca de uma maior qualidade foi considerada média ou inexistente. Quanto à periodicidade que a entidade gestora do circuito promove reuniões entre os associados, constatou-se que $56 \%$ se reúnem mensalmente, $22 \%$ bimensalmente e $22 \%$ relataram não realizar reuniões.

A maior parte dos gestores entrevistados considera como bom o grau de interatividade entre os circuitos, sendo que o contato entre eles ocorre predominantemente em eventos em que os circuitos são convidados. Daí a importância da Setur-MG manter os circuitos sempre em contato através da organização de eventos.

Os membros de um cluster devem sempre buscar atrair novas empresas, pois estes trazem novas idéias e o tornam cada vez mais sólido. Porém, deve ser estabelecido um padrão ao qual todos deverão se adequar. Diante da necessidade de captarem novos associados, os entrevistados relataram que as principais dificuldades na realização dessa tarefa são: a pouca informação por parte do empresariado, sua desconfiança, comodidade e falta de ousadia. Também foi revelada a baixa credibilidade do turismo como atividade segura para serem realizados investimentos e também a ausência de uma proposta atraente por parte dos circuitos. Gestores de circuitos localizados próximos a capital, Belo Horizonte, relataram ser mais difícil captar novas empresas no interior.

O desenvolvimento de qualquer setor deve se dar em consonância com as necessidades das comunidades envolvidas. No turismo essa preocupação deve ser ainda maior porque a atividade ocorre no local de residência desta comunidade. Quando a formação de um cluster é planejada, ou seja, não ocorreu espontaneamente, de acordo com Quandt apud Spinosa e Fisher (2003) os agentes locais devem participar de todo o processo, desde a fase de identificação das necessidades, vocações e potencialidades até a implementação das ações, tirando com isso o máximo proveito dos vínculos e das instituições já existentes na região. 
Todos os circuitos pesquisados demonstram possuir uma preocupação em fomentar um desenvolvimento que beneficie a região que estão inseridos. As principais ações desenvolvidas por eles nesse sentido foram: campanhas de conscientização dos alunos do ensino fundamental sobre a importância do turismo para o desenvolvimento de sua região; ações voltadas para a preservação do patrimônio histórico e do meio ambiente natural; campanha de sensibilização dos empresários locais sobre a necessidade de profissionalizar; incentivo aos municípios para criarem os Conselhos Municipais de Turismo, o que possibilita a participação de todas as classes na definição das metas para o turismo no município; apoio na realização de festas tradicionais da região.

A prosperidade de um circuito implicará em inúmeras conseqüências para a comunidade local. Dentre elas está a vinda de empresas de fora para a região com o intuito de explorar o turismo. De acordo com Porter (1989) essa chegada de novas empresas é benéfica porque os que vêm de fora podem ser mais capazes de perceberem novas oportunidades ou podem dispor de recursos diferentes que são necessários para competir de uma nova maneira. Porém, essas empresas competirão com as da região podendo levar os empresários locais à falência.

Dos gestores entrevistados, 90\% é a favor da vinda de empresas externas para explorar o turismo na região do circuito, desde que elas respeitem a comunidade local e o planejamento feito pelo circuito. Segundo os mesmos estas empresas gerarão mais empregos, trarão mais receitas, contribuirão com novas idéias e estimularão a competição interna. Apenas um gestor foi totalmente contra a vinda de empresas externas, alegando ser necessário preservar as empresas locais. Portanto, é predominante a visão de que a vinda de empresas externas é benéfica, porém deve-se fomentar o espírito empreendedor na comunidade local e ter sempre uma política de respeito aos interesses e a cultura local.

Acredita-se que a política de circuitos turísticos de Minas Gerais o pode ser caracterizada como uma maneira de induzir a formação de um cluster. Contudo as organizações atuam de maneira integrada, se complementando, visando oferecer um produto final único, que recebe o nome do circuito turístico.

O Quadro 01 busca demonstrar a relação entre as exigências da Setur-MG e os propósitos da concepção de cluster: 
Quadro 1- Exigências da Setur-MG X Conceito de Cluster

\begin{tabular}{c|l}
\hline EXIGÊNCIAS DA SETUR-MG & \multicolumn{1}{c}{ CONCEITO DE CLUSTER } \\
\hline Captação de novos associados & O cluster deve estar aberto a novos participantes. \\
\hline Apresentação das atas de reuniões trimestrais & $\begin{array}{l}\text { Os membros do cluster devem estar em contato } \\
\text { permanente (Estratégia Cooperativa). }\end{array}$ \\
\hline Pesquisa da Demanda & Estratégia de relacionamento com o cliente. \\
\hline Plano de Ação & $\begin{array}{l}\text { Os membros do cluster devem, juntos, planejarem } \\
\text { quais as ações serão realizadas. }\end{array}$ \\
\hline Roteiros Formatados & $\begin{array}{l}\text { Deve haver a união de esforços para oferecer um } \\
\text { produto com qualidade diferenciada (estratégia } \\
\text { competitiva). }\end{array}$ \\
\hline $\begin{array}{c}\text { Objetivar o desenvolvimento regional sustentável } \\
\text { do turismo }\end{array}$ & $\begin{array}{l}\text { É necessário que os agentes locais participem do } \\
\text { processo de desenvolvimento do cluster. }\end{array}$ \\
\hline
\end{tabular}

Fonte: Dados da Pesquisa

Finalmente, acredita-se que dos 45 que a Setur-MG buscou trabalhar, aproximadamente 15 serão certificados e se afirmarão como produtos turísticos. Cabe ressaltar que os circuitos do Ouro e das Águas já realizavam reuniões antes da política estadual. Portanto, a iniciativa do governo de Minas Gerais foi relevante, pois até então se desconhece uma mobilização com essa abrangência, desempenhada com tamanha seriedade por parte do poder público e que já apresenta resultados.

\section{Conclusão}

Considerando a teoria estudada e os dados coletados, podem ser elaboradas algumas conclusões acerca da política de circuitos turísticos adotada pelo governo Minas Gerais. Primeiramente acredita-se que para superar as dificuldades relatadas pelos circuitos, as entidades devem administrar a cadeia do turismo como um sistema integrado e não como partes separadas. Por isso, a aplicação do conceito de cluster é importante para que os circuitos possam atuar de forma planejada, cooperada e competitiva.

Ao percorrer um circuito, o turista espera que as empresas atuem de forma integrada e a qualidade nos serviços prestados seja uniforme. O não atendimento de suas expectativas por pelo menos uma das empresas pode prejudicar a imagem de todo o circuito. Como em qualquer cluster, os participantes devem buscar a cooperação mútua para que possam oferecer produtos e serviços de qualidade. Como instrumento de controle e incentivo à qualidade, 
poderia ser montado um método de avaliação dos serviços prestados pelas empresas e municípios participantes do circuito. Aqueles que atendessem aos critérios estabelecidos receberiam uma certificação (Selo de Qualidade) emitida pelo circuito.

O contato, a união e a confiança mútua constituem-se em estratégias competitivas dos membros de um cluster. Esta relação pode se tornar melhor através de palestras, reuniões, fóruns, ou eventos de confraternização.Os membros devem debater sobre o turismo, sempre em busca da qualidade dos serviços prestados. A internet deve ser utilizada como um canal de comunicação para os circuitos. Pode ser criada uma home page do circuito que, além de constituir-se em um meio de divulgação, disponibilizará uma central de reservas das empresas associadas e um fórum de discussão on-line entre os associados.

É necessário que os circuitos também mantenham contato entre si, para que assim possam trocar informações sobre o mercado, discutirem as ações da Secretaria Estadual de Turismo e proporem medidas para o Estado. A Setur-MG disponibiliza fóruns de discussão para os circuitos no site www.descubraminas.com.br e realiza periodicamente reuniões entre os gestores. Mas acredita-se que estas ações poderiam ser intensificadas

Para convencer novas organizações a associarem devem ser mostrados os benefícios que o circuito pode oferecer como: a reputação da marca, divisão de custos na realização de investimentos, maior poder nas negociações, aumento da taxa de permanência do turista. Porém ao captar novos associados deve-se atentar para o tamanho que o circuito irá adquirir. Circuitos muito grandes são difíceis de serem administrados e acabam perdendo a semelhança turística que deve haver entre os municípios participantes.

Acredita-se que apesar das relações entre as organizações, especialmente no setor privado, ainda não serem harmoniosas, estão cedendo espaço para um relacionamento de parceria e confiança. Nesse sentido a concepção de cluster é extremamente válida para demonstrar às organizações a importância de se articularem a fim de alcançarem uma maior competitividade

O motivo de alguns circuitos não terem progredido pode estar relacionado ao fato da política ter sido imposta pelo estado, e não um sentimento nascido entre as organizações locais. Contudo, percebe-se a importância de estudos futuros dedicarem-se à compreensão dos aspectos relacionados à ação coletiva que causaram esta resistência. Estes estudos forneceriam instrumentos para incentivar novos circuitos a aderirem às propostas do estado. 
Com o estudo percebeu-se que a política de circuitos turísticos adotada em Minas Gerais, apresenta semelhança com a concepção de cluster. Também ficou evidente a possibilidade da concepção de cluster auxiliar administradores públicos e gestores dos clusters turísticos no desempenho de suas tarefas.

Enfim, considerando o expressivo potencial turístico de Minas Gerais, acredita-se que a política de circuitos turísticos constitui-se em um instrumento de grande relevância para a utilização do turismo para desenvolver da economia do estado. Contudo, apesar dos circuitos apresentarem alguns aspectos que devem ser ajustados, acredita-se que as proposições acerca de cluster podem contribuir para a sua evolução e a conseqüente consolidação de Minas Gerais como um destino turístico.

\section{Referências Bibliográficas}

ACERENZA, Miguel Angel. 2002. Administração do Turismo: conceituação e organização. Bauru, SP: Edusc.

ALENCAR, Edgar.2003. Pesquisa Social e Monografia. Lavras: UFLA/FAEPE.

AMATO NETTO, João. 2000. Redes de Cooperação Produtiva e clusters regionais: oportunidades para as pequenas e médias empresas. São Paulo: Atlas: Fundação Vanzolini.

BENI, Mário Carlos. 2001. Análise Estrutural do Turismo. São Paulo: Editora SENAC. São Paulo.

BOLSON, Jaísa H. Gontijo. Circuitos Turísticos de Minas Gerais. Disponível em: <http:// www.estudosturisticos.com.br>. Acesso em: 08 dez. 2003.

CAPRA, Fritjof. 2002. As Conexões Ocultas: Ciências para uma vida sustentável. São Paulo: Editora Cultrix.

CLUSTER.. S/D. Cluster de Entretenimento da Bahia. Disponível em: <www.cluster.org.br.> Acesso em 13 jun. 2004.

CRUZ, Rita de Cássia. 2001. Política de Turismo e Território. São Paulo: Contexto.

GIDDENS, Anthony. 2001. Em Defesa da Sociologia. São Paulo: UNESP.

PETROCCHI, Mário. 2001. Gestão de Pólos Turísticos. São Paulo: Futura.

PORTER, Michael E. 1989. A Vantagem Competitiva das Nações. Rio de Janeiro: Campus.

PORTER, Michael E. 1998. Cluster and the new economics of competition. In: Harvard Business Review, Nov.-Dec.

SPINOSA, Luiz Márcio; FISHER, Letícia Mirella. 2003. Anais de Resumos / XXIII Encontro Nacional de Engenharia de Produção; editores José Luis D. Ribeiro [et. al.]. Porto Alegre: Abepro. 
TOLEDO, G. C et al. mai. 2002. Configuración del Turismo en el Ambiente Globalizado. Estudio de Casos de Clusters Turísticos. Turismo em Análise: São Paulo.

Recebido em: 15/07/2005 (1 ${ }^{\mathrm{a}}$ versão) $09 / 06 / 2006$ ( $2^{\mathrm{a}}$ versão)

Aprovado em: 16/08/2006 